\title{
Definition
}

This term refers to soft tissue tumors with two or more lines of differentiation. Both benign mesenchymoma and malignant mesenchymoma cases have been reported. Of note, mesenchymomas of the bone have also been described.

The World Health Organization suggests that this should not be considered a separate nosological entity but rather as a group of neoplasms with a prevalent differentiation with coexistence of additional cell elements of different origin.

Examples are liposarcoma with cartilaginous metaplasia and/or osteogenic areas, malignant peripheral nerve sheath tumor with heterologous elements (which can be observed in about $15 \%$ of cases; $\rightarrow$ see Chap. 244), the (rare) leiomyosarcomas with osteosarcoma-like or rhabdomyosarcomatous zones, and the (rare) embryonal rhabdomyosarcomas presenting with focal cartilage.

\section{Suggested Readings}

Argintar (2012) Soft-tissue benign mesenchymoma in a pediatric patient. Am J Orthop (Belle Mead NJ) 41(12):561-564

Brannan (2003) Malignant mesenchymoma of the orbit: case report and review of the literature. Ophthalmology 110(2):314-317

Fletcher (2020) WHO classification of tumours of soft tissue and bone (5th edition)

Gambarotti (2017) Fibrocartilaginous mesenchymoma of bone: a single-institution experience with molecular investigations and a review of the literature. Histopathology 71(1):134-142

Melton (2006) Benign mesenchymoma of the mediastinum: a report and review of the literature. Thorac Surg Sci 3:Doc02

Yang (2017) Primary malignant mesenchymoma of bladder: case report and review of the literature. Medicine (Baltimore) 96(32):e7579 